\title{
AVALIAÇÃO DO CONSUMO DE PALMITO DE PUPUNHA NO LITORAL DO PARANÁ EVALUATION OF CONSUMPTION OF HEART-OF-PALM OF THE PEJIBAYE IN THE COAST OF PARANÁ
}

\author{
Adilson ANACLETO ${ }^{1}$ \\ Márcia ROTHBART ${ }^{2}$ \\ Neiva Maria FIORENTIN² \\ Patrícia Andrioli de SOUZA ${ }^{2}$ \\ Rosani Kruger PRESTES ${ }^{2}$
}

\section{RESUMO}

A Bactris gasipaes Kunth é uma palmácea que produz o palmito utilizado na alimentação humana, popularmente conhecida como pupunha. É uma palmeira resultante da domesticação de várias espécies silvestres, portanto uma planta não extrativista, sendo considerada alternativa econômica a produtores rurais. No litoral do Paraná, região onde tradicionalmente é industrializado palmito de espécies nativas, a partir de 2000 ocorreu um crescimento de áreas cultivadas da pupunha. A pupunha continua tendo restrições no momento da comercialização do produto industrializado devido ao sabor adocicado da espécie. A pesquisa teve por proposta avaliar a aceitação ou rejeição no consumo do palmito de pupunha em conserva em comparação com o palmito Jussara (Euterpe endules), espécie de maior aceitação popular na região da pesquisa. Um total de 80 indivíduos participaram da avaliação sensorial, que foi acompanhado de um questionário de caracterização do perfil do consumidor. O preço do palmito foi o principal fator de influência no consumo. O palmito de pupunha quando avaliado em testes cegos não sofre rejeição dos consumidores.

Palavras- Chave: Palmaceae; Palmito de pupunha; Bactris gasipaes; Litoral do Paraná.

\section{ABSTRACT}

The Bactris gasipaes Kunth is a palm that produces the heart of palm used in the human feeding, popularly known as pejibaye. It is a resultant palm tree from the domestication of several wild species, therefore a no extractivist plant, being considered an economic alternative to the agricultural producers. In the Paraná coast, the region where traditionally it is industrialized native species of heart of palm, from 2000 started to occur a growth of cultivated areas of pejibaye. The pejibaye palm continues having restrictions at the industrialization product commercialization moment due to the sweet flavor of the species. The research had the proposal to evaluate the acceptance or rejection in the consumption of this heart of palm (pejibaye) in conserve in comparison to the heart of palm Jussara (Euterpe endules), species of larger popular acceptance in the region of the research. A total of 80 individuals participated of the sensorial evaluation, which had a questionnaire of consumer profile characterization. The price of the heart of palm was the main influence factor of consumption. The pejibaye heart of palm when evaluated in blind tests does not suffer rejection from the consumers.

Key-words: Palmaceae; Heart of palm of pejibaye; Bactris gasipaes; Coast of Paraná.

\footnotetext{
${ }^{1}$ Administrador de Empresas, Doutorando em Produção Vegetal-UFPR,Docente ISEPE Guaratuba, Travessa Vanessa 7, Guaratuba -PR, 83 280-000. adilsonanacleto@onda.com.br

${ }^{2}$ Bacharel em Administração de Empresas, Departamento de Administração, ISEPE, Rua Menelau Torres 101, 83280-000. Guaratuba - PR.
} 
ANACLETO, A. et al. Avaliação do consumo de palmito...

\section{INTRODUÇÃO}

O Brasil é a nação maior produtora de palmito no mundo, porém, por envasar produtos oriundos em sua maioria do extrativismo, gera danos ao meio ambiente. Uma importante alternativa para a reversão desta situação é a industrialização do palmito da palmeira Bactris gasipaes Kunth (Galdino e Clemente, 2008).

Popularmente conhecida como pupunha ou pupunheira, esta palmeira pode gerar vários caules com até $15 \mathrm{~m}$ de altura, tendo 15 a $25 \mathrm{~cm}$ de diâmetro, possuindo pontas agudas, marrons ou cinzas. O uso para fins de alimentação humana ocorre em média quando as plantas atingem mais de dois anos (Silva et al., 2006).

O estirpe da palmeira é usado para fabricação de artesanatos e móveis e as suas folhas para coberturas de casas, porem sua principal finalidade é a utilização do palmito como alimento humano, que é muito comercializado no Brasil.

O palmito da pupunha apresenta sabor levemente adocicado e agradável e alto valor nutritivo, destacando-se elevados teores de caroteno de proteína e de gordura (Bernardi et al., 2003), assim como fornece muitos minerais, pois contém sódio, potássio, manganês, cálcio, ferro, flúor, cobre, boro e silício (Bernardi et al., 2007).

Além do Brasil, muitos países da América Latina têm investido no cultivo e na industrialização do palmito da pupunha. Sendo considerada de fácil cultivo, oferecendo vantagens significativas em relação a outras espécies (Bernardi et al., 2007), sobretudo em se tratando da expansão para o mercado nacional e internacional (Yuyama et al., 2005).

$\mathrm{Na}$ década de 1990, o cultivo da pupunheira para a produção de palmito despertou o interesse de agricultores de todo o Brasil, principalmente, na busca de novas opções de cultivo em substituição às palmeiras nativas e de longo ciclo (Bergo et al., 2002).

A vantagem da pupunha sobre as espécies tradicionais consiste especialmente na sua precocidade e capacidade de formar perfilhos o que favorece a produção continuada (Silva et al., 2006) e a padronização dos toletes, porção foliar destinada a industrialização (Galdino e Clemente, 2008)

Atualmente a pupunha cultivada no Brasil é o resultado do melhoramento da espécie que deu origem a variedades sem espinhos e mais produtivas. Os locais favoráveis para sua produção são as regiões de clima tropical, e o cultivo da espécie é considerado economicamente lucrativo (EMBRAPA, 2004; Gomes et al., 2006)

O litoral do Paraná apresenta clima tropical, isento de geadas e elevados índices de pluviosidade, portanto apto ao cultivo da pupunha, uma espécie que a partir de 1990 tem sido amplamente cultivada na região (Santos et al., 2001), onde tradicionalmente se industrializa o palmito Jussara (Euterpe edulis Mart.).

A pupunha apresenta relevância ecológica, uma vez que se trata de planta não endêmica do sul do Brasil.Toda sua produção advém de cultivo, em contraposição à preocupante situação no litoral do Paraná, onde o palmito Jussara sofre forte pressão do extrativismo ilegal para industrialização, sendo muitas vezes adquirido com tamanho inadequado. Este extrativismo tem provocado o decréscimo contínuo das populações desta espécie nativa largamente consumida nesta região (Tonetti e Negrelle, 2001).

O caráter sustentável da pupunha aliado a possibilidade de uma alternativa econômica aos produtores (Bergo et al., 2002) motivou a presente pesquisa que buscou identificar os níveis de aceitabilidade do palmito de pupunha em conserva para o consumo humano.

Assim a pesquisa teve como proposta avaliar a aceitação ou rejeição do palmito da pupunha quando comparado ao palmito Jussara, com base em análise sensorial.

\section{MATERIAL E MÉTODOS}

O método de pesquisa envolveu uma investigação caracterizada como experimento de campo e foi realizada em ambiente próximo ao cultivo e extrativismo do palmito, bem como de sua industrialização.

Conservas industriais de palmitos de pupunha e de Jussara adquiridas em fornecedores da região litorânea do Paraná foram utilizadas para a avaliação sensorial, sendo estas empresas devidamente certificadas, garantindo assim a procedência e a qualidade do palmito.

A caracterização dos consumidores de palmito relativo a renda, gênero, freqüência de compra e os fatores de influência na compra do palmito, deu-se pelo preenchimento de um questionário estruturado, antes do inicio da avaliação sensorial.

O teste sensorial consistiu em avaliar as características organolépticas de cor, textura, aroma e sabor dos palmitos de pupunha e Jussara, caracterizando a amostragem e tendo o provador a possibilidade de repetição se fosse solicitada.

A amostragem foi constituída por $60 \%$ de indivíduos do sexo feminino e $40 \%$ do sexo masculino, sendo que a idade média dos participantes foi de 31 anos o que retratou um importante perfil da população economicamente ativa (IBGE, 2009).

De acordo com o número das fichas dos entrevistados voluntários, os números pares receberam amostras da espécie Jussara e os números ímpares em igual procedimento da espécie pupunha. A cada repetição a ordem de análise das espécies foi invertida.

Todos os questionários foram aplicados no mesmo dia (13 de novembro de 2009) dividido em grupos de 20 indivíduos para quatro locais diferentes, perfazendo um total de 80 indivíduos de acordo com o proposto por Malhotra (2001) e Bernardi et al. (2003).

Os palmitos usados para a avaliação sensorial foram previamente cortados em rodelas de aproximadamente $5 \mathrm{~mm}$, e estas foram colocadas individualmente em pratos de plástico branco descartáveis. 
ANACLETO, A. et al. Avaliação do consumo de palmito...

As embalagens do produto palmito em conserva não continham indicação que identificasse a marca ou fabricante. Portanto estas informações não influenciaram as respostas dos julgadores.

O julgador voluntário recebeu uma ficha contendo quatro características organolépticas: cor, aroma, textura e sabor. Foi utilizada a escala somatória ou escala de Likert com dez pontos para avaliação do grau atribuído pelo julgador.

A avaliação foi realizada no município de Guaratuba, sendo a distribuição baseada na classe social de acordo com o critério Brasil de renda econômica (Abep, 2009).

Foi convencionado previamente que os primeiros 16 formulários de cada classe econômica seriam selecionados para as análises estatísticas de acordo com o critério Brasil das classes $A$ até $E$.

A homogeneidade das variâncias foi determinada pelo teste de Bartlett e para a comparação de médias das notas atribuídas na avaliação sensorial foi usado o teste de Tukey ao nível de 0,05 de probabilidade.

\section{RESULTADOS E DISCUSSÃO}

Constatou-se que o consumidor de palmito independente da classe econômica e embora residindo numa região produtora não conhece em profundidade a respeito do produto palmito em conserva, pois, $47,5 \%$ dos entrevistados não souberam citar o nome de nenhuma espécie de palmito.

Relativo ao consumo de palmito, a espécie Jussara foi considerada pelos entrevistados como preferida ao consumo (43\%) seguida pelo palmito de pupunha (30\%), palmeira real e açaí $(8,7 \%)$.

Segundo Cobra (1992) a freqüência de consumo de determinado produto pode definir o sucesso ou extinção de determinado segmento produtivo. O estudo atual registra que $29,9 \%$ do total dos entrevistados consomem acima de três vidros de palmito por mês (Tabela 1), um valor considerado relevante, para um produto de custo elevado como o palmito envasado. Também o estudo identificou um real potencial para ampliação do consumo de palmito, uma vez que $25 \%$ dos entrevistados consomem menos de um vidro ao mês (Tabela 1).

TABELA 1 - Freqüência mensal de consumo de palmito de acordo com a classificação econômica $(n=80)$.

\begin{tabular}{cc}
\hline Classe social & $\begin{array}{l}\text { Unidades de conservas de palmito consumidas } \\
\text { Mensalmente e independente da espécie }\end{array}$ \\
\hline A & 4 \\
B & 4 \\
C & 2 \\
D & 1 \\
E & 0
\end{tabular}

As médias de consumo mensal estão relacionadas com à renda financeira. Nas classes econômicas $C$ e $D$ o palmito é considerado iguaria em ocasiões especiais como aniversários e outras comemorações. Porém esta situação merece especial atenção, pois segundo Paduan (2009) o consumo de produtos supérfluos na classe $C$ tem se elevado consideravelmente e a estimativa é de que em média $8 \%$ do orçamento anual de 554 bilhões de reais desta classe sejam destinados ao consumo de supérfluos. Assim, o consumo de palmito nesta classe econômica merece análise mais aprofundada, uma vez que pode representar significativo potencial de ampliação.

O preço foi considerado o principal fator associado ao consumo de palmito. No ato da compra do palmito o preço foi descrito como relevante por $66 \%$ dos entrevistados (Figura 1). Segundo Cobra (1992) este fator influencia decisivamente o comportamento do consumidor devido à composição da renda econômica familiar, assim, isto pode ter sido a justificativa para a elevada diferença nas médias de consumo (Tabela 1) observada entre as classes econômicas participantes.

Não somente os fatores econômicos, como preço e renda são determinantes no comportamen- to do consumidor e outros elementos são igualmente significativos, como o da racionalidade do consumidor, que influencia muito nas decisões de compra (Farias e Santos, 2000). Segundo Bernardi et al. (2007) entre os fatores mais importantes que influenciam a preferência de uma espécie de palmito em relação a outra podem ser destacados o sabor, cor, formato e textura.

Os valores atribuídos no teste sensorial para as amostras de palmito de pupunha e Jussara não foram estatisticamente diferentes entre si para aroma , textura e cor (Tabela 2).

A pesquisa atual encontrou resultados similares aos descritos por Raupp et al. (2004) e Bernardi et al. $(2003 ; 2007)$ de que o palmito de pupunha possui boa aceitação no mercado, quando consideradas suas características organolépticas:cor amarelo-clara, textura macia e aroma suave.

O sabor foi a característica organoléptica das duas espécies avaliadas que obteve as melhores médias de avaliação (Tabela 3 ) e estas não diferiram estatisticamente entre si. 
ANACLETO, A. et al. Avaliação do consumo de palmito...

TABELA 2 - Avaliação sensorial de cor, aroma e textura de palmito em conserva das espécies pupunha e Jussara

\begin{tabular}{c|c|c|c|c|c|c|c|c|c} 
& \multicolumn{4}{|c|}{ Cor } & \multicolumn{3}{c|}{ Aroma } & \multicolumn{3}{c}{ Textura } \\
\hline & Média & $\mathrm{S} \pm$ & $\mathrm{C}_{\mathrm{v}}$ & Média & $\mathrm{S} \pm$ & $\mathrm{C}_{\mathrm{v}}$ & Média & $\mathrm{S}_{ \pm}$ & $\mathrm{C}_{\mathrm{v}}$ \\
Pupunha (A) & $5,9 \mathrm{a}$ & 1,8 & 0,30 & $7,3 \mathrm{a}$ & 1,7 & 0,23 & $7,6 \mathrm{a}$ & 1,7 & 0,22 \\
Jussara (B) & $5,9 \mathrm{a}$ & 1,9 & 0,32 & $6,9 \mathrm{a}$ & 1,2 & 0,17 & $7,5 \mathrm{a}$ & 1,9 & 0,25 \\
\hline
\end{tabular}

Médias seguidas de mesma letra não diferem estatisticamente entre si (Tukey $p<0,05$ ).

$\mathrm{S}=$ variância, $\mathrm{C}_{\mathrm{v}}=$ Coeficiente de variação

TABELA 3 - Avaliação sensorial do sabor de palmito em conserva das espécies pupunha e Jussara

\begin{tabular}{cccc}
\hline Espécie & Média & $\mathrm{S}_{ \pm}$ & $\mathrm{C}_{V}$ \\
\hline Pupunha & 7,7 & 1,4 & 0,18 \\
Jussara & 7,8 & 1,4 & 0,17 \\
\hline
\end{tabular}

Médias seguidas de mesma letra não diferem estatisticamente entre si $($ Tukey $p<0,05)$. $S=$ variância, $C_{v}=C_{0}-$ eficiente de variação

O palmito de pupunha sofre discriminação dos consumidores devido ao sabor adocicado característicda espécie (Gomes et al.,2006), porem na pesquisa atual a pupunha recebeu notas similares às atribuídas ao Jussara na avaliação sensorial. Isto pode ser explicado porque, segundo Raupp et al. (2004), nas conservas de palmito de pupunha que contenham salmouras com $3,5 \%$ ou $4,0 \%$ de sal esta condição adocidcada é minimizada. Assim dependendo da quantidade de sal na conserva o grau de doçura natural do palmito de pupunha torna-se imperceptível.

A similaridade das médias obtidas no teste cego para a pupunha e o palmito de Jussara, de maior preferência no mercado, reforça segundo Porter (2002) a busca de alternativas para estimular o consumo e promover maior visibilidade ao produto e em conseqüência ampliar o número de consumidores.

Entretanto Kotler (1998) ressalta que a mudança no comportamento do consumidor é muito difícil, por isso deve-se prover a divulgação massa das qualidades primordiais de um produto, e reforçar que os mesmos reconhecidamente satisfazem as necessidades dos seus clientes, quando comparados ao produto preferido e tido como referência, no caso o palmito Jussara.
Considerando que a pupunha teve boa aceitação no presente estudo, os resultados obtidos indicam que a expansão de consumo pode dar-se através de campanhas de marketing em conjunto com a demonstração e degustação em ambientes de compra ou consumo, como mercados, lanchonetes, restaurantes e feiras. Deve ser destacado também tratar-se de uma planta não extrativista, cultivada de modo ecologicamente correto, pois segundo Farias e Santos (2000) cada vez mais os consumidores buscam valores agregados, como o ecológico e os socialmente justos.

A aceitação da pupunha enquanto iguaria pode representar a redução da extração das várias espécies de palmitos nativos e preservação da flora nativa que segundo Borsato et al. (2007) apresenta crescentes níveis de degradação.

\section{CONCLUSÕES}

O preço do palmito é o fator relevante no processo decisório na compra das espécies pesquisadas.

O palmito de pupunha quando avaliado em teste cego, juntamente com o palmito Jussara, não sofre rejeição no consumo.

\section{REFERÊNCIAS}

1. ABEP. Critério de classificação econômica Brasil. Informativo técnico 01/2009. 2009. 4p.

2. BERGO, C. L.; MENDONÇA, H. A.; LEDO, F. J. Melhoramento Populacional da Pupunheira. Ministério da Agricultura e Abastecimento. Relatório de Pesquisa e Desenvolvimento, 1999-2001. EMBRAPA. Rio Branco, Acre, p. 33-34, 2002.

3. BORSATTO, R. S.; OTTMANN, M. M. A.; FONTE, N. N.; CIDADE JÚNIOR, H. A.; ALANO, E. R. C.;CAVALLET, V. C. Problemas agrários do litoral paranaense: abordagem histórica. Scientia Agraria, v. 8, n. 4, p. 421-430, 2007.

4. BERNARDI, M. R. V.; CAVALCANTI, A. C. D.; KAJISHIMA, S. Aceitabilidade do Palmito de Pupunha. CEPPA, v. 
21, n. 1, p. 121-130, 2003.

5. BERNARDI, M. R.V.; MORAES, C. W. S.; MACHADO, C. A.; KAJISHIMA, S.; COSTA, E. Q. Análise Descritiva Quantitativa do Palmito de Pupunheira. Acta Amazônica, v. 37, n. 4, p. 507-512, 2007.

6. COBRA, M. Administração de marketing: 2 ed. São Paulo: Atlas, 1992. 452p.

7. FARIAS, S. A.; SANTOS, R. C. Modelagem de equações estruturais e satisfação do consumidor: Uma investigação teórica e prática. Revista de Administração Contemporânea, v. 4, n. 3, p. 107-132, 2000.

8. GALDINO, N. O.: CLEMENTE, E. Palmito de pupunha (Bactris gasipaes Kunth.) composição mineral e cinética de enzimas oxidativas. Ciência e Tecnologia de Alimentos, v. 28, n. 3, p. 540-544, 2008

9. GOMES, M.; VALLE, J.; RAUPP, D. S.; CHAIMSOHN, F. P.; BORSATO, A. V. Processamento de Conservas de Palmito Caulinar de Pupunha Contendo Diferentes Graus de Acidez. Revista de Ciência e Agrotecnologia, v. 30, n. 3, p. 569-574, 2006.

10. IBGE, Instituto Brasileiro de Geografia e Estatística. Perfil da população economicamente ativa no Brasil. Disponível: http://www.ibge.gov.br/home/estatistica/indicadores/sipd/segundo_aspectos.shtm. Acesso em 10 de outubro de 2009.

11. KOTLER, P. Administração de marketing: a edição do novo milênio. 10 ed. São Paulo: Prentice Hall, 2000. $765 p$.

12. KOTLER, P. Administração de marketing: analise planejamento, implementação e controle. 5 ed. São Paulo: Atlas, 1998. 730p.

13. EMBRAPA. Levantamento de reconhecimento dos solos do litoral do Paraná. Curitiba: 128 p. EMBRAPA e IAPAR. Disponível em: http://www.cnptia.embrapa.br/boletim pesq.html//APAR. Acesso em: 12 de set. 2009.

14. MALHOTRA, N. K. Pesquisa de marketing: uma orientação aplicada. 3 ed. Porto Alegre: Bookman, 2001. 720p.

15. PADUAN, R. Para onde vai o dinheiro do consumidor. Exame, v. 6, n. 940, p. 22-39, 2009.

16. PORTER, M. Vantagem competitiva. 2 ed. Rio de Janeiro: Campus, 2002. 376p.

17. RAUPP, D. S.; ALMEIDA, F. C. C.; STARON, E. A.; VALLE, J.; BORSATO, A. V.; SANTOS, A. F. Conservas de Palmito de Pupunha em Diferentes Salmouras Avaliação Sensorial. Publicatio EUPG Ciências Exatas e da Terra, Ciências Agrárias e Engenharias, v. 10, n. 1, p. 27-33, 2004.

18. SANTOS, A. F.; TESMANN, D. J.; NUNES, W. M. C.; VIDA, J. B.; JACCOUD FILHO, D. S. Doenças foliares da pupunheira (Bactris gasipaes) no Estado do Paraná. Boletim de Pesquisa Florestal. EMBRAPA, Colombo, $\mathrm{n}$. 42, v.1, p. 141-145, 2001.

19. SILVA, V. L.; MÔRO, F. V.; FILHO, C. F. D.; MORÔ SILVA, Jr.; CHARLO, H. C. O. Morfologia e avaliação do crescimento inicial de plântulas de Bactris gasipaes Kunth. (arecaceae) em diferentes substratos. Revista Brasileira de Fruticultura, v. 28, n. 3, p. 477-480, 2006.

20. TONETTI, E. L; NEGRELLE, R. R. B. Dinâmica do banco de plântulas de palmito em ambiente natural. Scientia agraria, v. 2, n. 1-2, p. 79-85, 2001.

21. YUYAMA, K.; CHAVEZ F.: WANDERS, B.; PEREIRA, B. G.; SILVA, I. A. Efeito da densidade de plantas e da adubação NPK na produção inicial de palmito de pupunheira. Revista Brasileira de Ciência do Solo, v. 29, n. 3, p. 373-378. 2005

Recebido em 06/08/2010 Aceito em 17/03/2011 